\title{
Hearing characteristics of infantile-onset Pompe disease after early enzyme-replacement therapy
}

\author{
Chien-Yu Hsueh 1,2,3, , Chii-Yuan Huang ${ }^{2,3}$, Chia-Feng Yang 4,5, Chia-Chen Chang ${ }^{6}$, Wei-Sheng Lin ${ }^{4}$, \\ Hsiu-Lien Cheng ${ }^{2,7}$, Shang-Liang $\mathrm{Wu}^{8}$, Yen-Fu Cheng ${ }^{2,3,6,8,9^{*}}$ (D) and Dau-Ming Niu ${ }^{4,10^{*}}$
}

\begin{abstract}
Background: Studies suggest that enzyme-replacement therapy (ERT) is crucial to the survival of patients with infantile-onset Pompe disease (IOPD). Hearing impairment $(\mathrm{HI})$ is one of the clinical sequelae observed in long-term survivors. However, the benefits of early ERT for hearing outcomes have not yet been reported. This study aimed to investigate the impact of early ERT on IOPD patients.
\end{abstract}

Methods: This retrospective longitudinal study recruited IOPD patients who were referred by newborn screening for confirmatory diagnosis based on our rapid diagnostic criteria and received early ERT treatment between January 1 , 2010, and January 31, 2018. The hearing test battery included a tympanogram, otoacoustic emission, auditory brainstem evoked response (ABR), pure-tone audiometry or conditioned play audiometry.

Results: Nineteen patients with IOPD were identified, 6 of whom had hearing impairment ( $\mathrm{HI}) ; 1$ had conductive $\mathrm{HI}$, 2 had sensorineural $\mathrm{HI}$ (one had bilateral mild $\mathrm{HI}$ and one had mild $\mathrm{HI}$ in a single ear) and 1 had moderate mixed-type $\mathrm{HI}$. Two patients failed the newborn screening test and had mild $\mathrm{HI}$ in the ABR. The mean age of the initial time to ERT was $11.05 \pm 4.31$ days, and the $\mathrm{HI}$ rate was $31.6 \%(6 / 19)$.

Conclusion: Our study is the largest cohort to show the characteristic hearing outcomes of IOPD patients after ERT. Early ERT within 2 weeks after birth may contribute to better hearing outcomes. Clinicians should be vigilant in testing for the hearing issues associated with IOPD and should intervene early if any $\mathrm{HI}$ is detected.

Keywords: Infantile-onset Pompe disease, Enzyme-replacement therapy, Hearing loss, Congenital deafness, Lysosomal storage disorder, Glycogen storage disorder

\section{Introduction}

Pompe disease, which is also known as glycogen storage disorder type II or acid maltase deficiency, is an autosomal recessive lysosomal storage disorder that is caused by a deficiency of the lysosomal enzyme acid

\footnotetext{
*Correspondence: yfcheng2@vghtpe.gov.tw; dmniu@vghtpe.gov.tw

2 Department of Otolaryngology_-Head and Neck Surgery, Taipei Veterans General Hospital, Taipei, Taiwan

${ }^{4}$ Department of Pediatrics, Taipei Veterans General Hospital, No. 201, Sec 2, Shipai Rd., Beitou District, Taipei City 11217, Taiwan

Full list of author information is available at the end of the article
}

alpha-glucosidase (GAA) [1-4]. The incidence of Pompe disease is variable; it occurs in an estimated 1 in 14,000 to 600,000 people worldwide, depending on ethnicity and geographic region [2, 5-10].

Pompe disease leads to the progressive accumulation of glycogen in specific organs and tissues, especially muscular (skeletal, cardiac and smooth muscles) and nervous tissues, causing abnormal motor and neural functions, including hearing loss. The presentation of glycogen storage in the organ of Corti in a knockout mouse model of Pompe disease, including in the inner and outer hair cells, original author(s) and the source, provide a link to the Creative Commons licence, and indicate if changes were made. The images or other third party material in this article are included in the article's Creative Commons licence, unless indicated otherwise in a credit line to the material. If material is not included in the article's Creative Commons licence and your intended use is not permitted by statutory regulation or exceeds the permitted use, you will need to obtain permission directly from the copyright holder. To view a copy of this licence, visit http://creativecommons.org/licenses/by/4.0/. The Creative Commons Public Domain Dedication waiver (http://creativeco mmons.org/publicdomain/zero/1.0/) applies to the data made available in this article, unless otherwise stated in a credit line to the data. 
the supporting cells, the stria vascularis, and the spiral ganglion neurons, suggests that this hearing impairment may be related to a cochlear pathology $[11,12]$.

This disease shows an extremely wide spectrum of symptom severity and is usually classified into three categories according to the time of onset: infantile-onset Pompe disease (IOPD) and late-onset Pompe disease (LOPD), and in between, non-classical infantile-onset Pompe disease [13, 14]. Patients with IOPD usually show hypotonia, muscle weakness, motor delay, feeding problems, and respiratory insufficiency right after the birth $[13,15]$. Most IOPD patients experience fatal symptoms within the first year of life and cannot survive for more than two years without treatment $[13,14,16]$.

Early enzyme-replacement therapy (ERT) with recombinant human alpha-glucosidase can improve the survival rate, reverse cardiomyopathy, and improve motor function in patients with Pompe disease [15-19]. Although ERT significantly increases survival, other clinical sequelae, including hearing loss and cognitive developmental delays, have been observed in long-term survivors with IOPD $[15,20]$. Currently, hearing loss is recognized as an important cause of morbidity in IOPD patients. The auditory dysfunction of IOPD patients has been described in several studies; the most common type of hearing impairment is the sensorineural type [12, $13,15,20-23]$.

As in other lysosomal storage disorders, while there is a consensus in favor of early ERT before the occurrence of irreversible damage when treating IOPD [13], our previous study also showed that very early identification and initiation of ERT allows for better patient outcomes [24]. However, the benefits of early ERT in terms of hearing outcomes have not yet been reported. In this study, we investigated the hearing function of IOPD patients who received early ERT, starting around 11 days old. We also reviewed and discussed the hearing outcomes of other groups of patients who began receiving ERT at various times after birth.

\section{Materials and methods Study population}

In Taiwan, Pompe disease has been included in the nationwide newborn screening program since 2008 . This study included children who were referred to Taipei Veterans General Hospital (TVGH) and received a confirmed diagnosis of IOPD between January 1, 2010 and January 31, 2018. After 2010, all the referred newborns were given ERT starting within $4 \mathrm{~h}$ of admission if they had the following manifestations: (1) general hypotonia; (2) an elevated creatine kinase level ( $>250 \mathrm{~m} / \mathrm{L})$; (3) extremely low GAA activity upon initial dried blood spot analysis $(<0.50 \mathrm{mmol} / \mathrm{L} / \mathrm{h})$; and
(4) a high left ventricular mass index $(>80 \mathrm{~g} / \mathrm{m} 2)$ [24, 25]; confirmatory diagnoses using GAA gene sequencing was usually performed in 5 days passing their newborn hearing screenings, while two patients failed. The Institutional Review Board (IRB) of the Taipei Veterans General Hospital approved this study (IRB No.2020-11-004AC). All the procedures performed in studies involving human participants were in accordance with the ethical standards of the institutional and/or national research committee and with the 1964 Helsinki declaration and its later amendments or comparable ethical standards.

\section{Audiometric measures}

Newborn hearing screening was performed by automatic auditory brainstem evoked response (aABR) after birth. Behavioral test techniques, such as conditioned play audiometry (CPA), were applied for patients under 5 years old. Pure-tone threshold testing was performed for both air conduction and bone conduction. The average air conduction thresholds at frequencies of 500, 1,000, and 2,000 Hz were used to classify the type of hearing loss (the conductive component in case of an air-bone gap of $\geq 15 \mathrm{~dB}$ ) and to grade the amount of hearing loss according to the American Speech-Language-Hearing Association (ASHA) definition of the degree of hearing loss [26]. The degree of hearing loss was classified as normal $(<-10$ and $\leq 15 \mathrm{~dB}$ HL), slight $(>15$ and $\leq 25 \mathrm{~dB}$ $\mathrm{HL})$, mild ( $>25$ and $\leq 40 \mathrm{~dB} \mathrm{HL})$, moderate $(>40$ and $\leq 55 \mathrm{~dB} \mathrm{HL})$, moderately severe $(>55$ and $\leq 70 \mathrm{~dB}$ $\mathrm{HL})$, severe (>70 and $\leq 90 \mathrm{~dB} \mathrm{HL})$, or profound ( $>90 \mathrm{~dB} \mathrm{HL}$ ). Two patients underwent threshold auditory brainstem evoked response (TABR) measurements when they were 0.3 and 1.1 years of age. The waveforms were analyzed by an experienced audiologist, who defined the latency of peak V. The amount of hearing loss was estimated from the detection threshold of peak $\mathrm{V}$. The hearing level thresholds as estimated by TABR were categorized as normal $(<25$ and $\leq 35 \mathrm{~dB} \mathrm{nHL}$ ), mild ( $>35$ and $\leq 45 \mathrm{~dB} \mathrm{nHL}$ ), moderate ( $>45$ and $\leq 65 \mathrm{~dB} \mathrm{nHL}$ ), severe ( $>65$ and $\leq 90 \mathrm{~dB}$ $\mathrm{nHL}$ ), or profound (>90 dB nHL) hearing loss [27]. Regarding the tympanometry, the tympanograms were classified as type A, As, Ad, B, or C according to Jerger (1970) [28].

\section{Statistical analysis}

The quantitative data were summarized as the means \pm standard deviation (SD), and the categorical variables were summarized as percentages. All the statistical analyses were performed using IBM SPSS 20.0 software (IBM Corp., Armonk, NY, USA). 
Table 1 Patient characteristics of 19 patients with IOPD

\begin{tabular}{|c|c|c|c|c|c|c|}
\hline Patient no. $(n=19)$ & Sex & $\begin{array}{l}\text { GA, week, BBW } \\
(\mathrm{kg})\end{array}$ & $\begin{array}{l}\text { Age at referral } \\
\text { (day) }\end{array}$ & $\begin{array}{l}\text { Age at first ERT } \\
\text { (day) }\end{array}$ & $\begin{array}{l}\text { End of study age } \\
\text { (year) }\end{array}$ & GAA mutation \\
\hline 1 & $\mathrm{~F}$ & $37,3.2$ & 18 & 18 & 9.5 & $\begin{array}{l}\text { c.1411_1414del, (E471fsX5), het- } \\
\text { erozygous } \\
\text { c.872T } \rightarrow \text { C, (p.L291P) heterozygous }\end{array}$ \\
\hline 2 & M & $38,3.5$ & 15 & 15 & 8.4 & $\begin{array}{l}\text { c. } 1935 \text { C } \rightarrow \text { A, (p.D645E), homozy- } \\
\text { gous } \\
\text { c.1726 G } \rightarrow \text { A, (p.G576S), homozy- } \\
\text { gous }\end{array}$ \\
\hline 3 & M & $39,3.3$ & 9 & 9 & 8.4 & $\begin{array}{l}\text { c.1935 C } \rightarrow \text { A, (p.D645E), heterozy- } \\
\text { gous } \\
\text { c.2303 C } \rightarrow \text { T, (p.P768L), heterozy- } \\
\text { gous }\end{array}$ \\
\hline 4 & M & $38,3.1$ & 12 & 12 & 8 & $\begin{array}{l}\text { c.1396 G } \rightarrow \text { T, (p.V466F), heterozy- } \\
\text { gous } \\
\text { c.1935 C } \rightarrow \text { A, (pD645E), heterozy- } \\
\text { gous }\end{array}$ \\
\hline 5 & $\mathrm{~F}$ & $39,3.0$ & 9 & 9 & 7.5 & $\begin{array}{l}\text { c. } 1935 \mathrm{C} \rightarrow \mathrm{A} \text {, (p.D645E), homozy- } \\
\text { gous } \\
\text { c.1726 G } \rightarrow \text { A, (p.G576S), homozy- } \\
\text { gous }\end{array}$ \\
\hline 6 & $\mathrm{~F}$ & $39,3.1$ & 8 & 23 & 6.5 & $\begin{array}{l}\text { c.2238 G } \rightarrow \text { C, (p.W746C), heterozy- } \\
\text { gous } \\
\text { c.2237 G } \rightarrow \text { A, (p.W746X), heterozy- } \\
\text { gous } \\
\text { c.1726 G } \rightarrow \text { A, (p.G576S), heterozy- } \\
\text { gous }\end{array}$ \\
\hline 7 & $\mathrm{~F}$ & $34,2.2$ & 12 & 12 & 6.5 & $\begin{array}{l}\text { c.1935 C } \rightarrow \text { A, (pD645E), heterozy- } \\
\text { gous } \\
\text { IVS7 }+2 T \rightarrow C \text {, heterozygous } \\
\text { c.1726 G } \rightarrow \text { A, (p.G576S), heterozy- } \\
\text { gous }\end{array}$ \\
\hline 8 & M & $39,3.7$ & 7 & 7 & 6.4 & $\begin{array}{l}\text { IVS7 }+2 \mathrm{~T} \rightarrow \mathrm{C} \text {, heterozygous } \\
\text { c.1935 C } \rightarrow \text { A, (p.D645E), heterozy- } \\
\text { gous } \\
\text { c.1726 G } \rightarrow \text { A, (p.G576S), heterozy- } \\
\text { gous }\end{array}$ \\
\hline 9 & $\mathrm{~F}$ & $39,2.9$ & 13 & 13 & 6 & $\begin{array}{l}\text { c.1082 C } \rightarrow \text { T, (p.P361L), heterozy- } \\
\text { gous } \\
\text { c.1935 C } \rightarrow \text { A, (p.D645E), heterozy- } \\
\text { gous } \\
\text { c.1726 G } \rightarrow \text { A, (p.G576S), heterozy- } \\
\text { gous }\end{array}$ \\
\hline 10 & $\mathrm{~F}$ & $39,2.9$ & 10 & 10 & 5.7 & $\begin{array}{l}\text { c. } 1935 \mathrm{C} \rightarrow \mathrm{A} \text {, (p.D645E), homozy- } \\
\text { gous } \\
\text { c.1726 G } \rightarrow \text { A, (p.G576S), homozy- } \\
\text { gous }\end{array}$ \\
\hline 11 & $\mathrm{~F}$ & $41,2.6$ & 6 & 6 & 5.6 & $\begin{array}{l}\text { c. } 1935 \mathrm{C} \rightarrow \mathrm{A} \text {, (p.D645E), homozy- } \\
\text { gous } \\
\text { c.1726 G } \rightarrow \text { A, (p.G576S), homozy- } \\
\text { gous }\end{array}$ \\
\hline 12 & $\mathrm{~F}$ & $36,3.3$ & 8 & 8 & 4.8 & $\begin{array}{l}\text { c.1411_1414del, (E471fsX5), het- } \\
\text { erozygous } \\
\text { c.1935 C } \rightarrow \text { A, (pD645E), heterozy- } \\
\text { gous } \\
\text { c.1726 G } \rightarrow \text { A, (p.G576S), heterozy- } \\
\text { gous }\end{array}$ \\
\hline 13 & M & $39,2.5$ & 13 & 13 & 4.6 & $\begin{array}{l}\text { c.1726 G } \rightarrow \text { A, (p.G576S), heterozy- } \\
\text { gous } \\
\text { c.1935C } \rightarrow \text { A, (pD645E), heterozy- } \\
\text { gous } \\
\text { c.2274insC, (p.G759fs), heterozy- } \\
\text { gous }\end{array}$ \\
\hline
\end{tabular}


Table 1 (continued)

\begin{tabular}{|c|c|c|c|c|c|c|}
\hline Patient no. $(n=19)$ & Sex & $\begin{array}{l}\text { GA, week, BBW } \\
(\mathrm{kg})\end{array}$ & $\begin{array}{l}\text { Age at referral } \\
\text { (day) }\end{array}$ & $\begin{array}{l}\text { Age at first ERT } \\
\text { (day) }\end{array}$ & $\begin{array}{l}\text { End of study age } \\
\text { (year) }\end{array}$ & GAA mutation \\
\hline 14 & $\mathrm{~F}$ & $39,3.1$ & 7 & 8 & 2.4 & $\begin{array}{l}\text { c.1935 C } \rightarrow \text { A, (p.D645E), homozy- } \\
\text { gous } \\
\text { c.1726 G } \rightarrow \text { A, (p.G576S), homozy- } \\
\text { gous }\end{array}$ \\
\hline 15 & $\mathrm{~F}$ & $38,3.5$ & 7 & 9 & 3.1 & $\begin{array}{l}\text { c.1411_1414del, (E471fsX5), het- } \\
\text { erozygous } \\
\text { c.752C > T;c.761 C>T,p.S251L; S254L } \\
\text { c. } 1843 \text { G > A,p.G615R }\end{array}$ \\
\hline 16 & $\mathrm{~F}$ & $37,3.1$ & 9 & 10 & 3 & $\begin{array}{l}\text { c.1636+10 C>T } \\
\text { c.2024_2026del,p.N675del } \\
\text { c.241 C>T,p.Q81* }\end{array}$ \\
\hline 17 & $\mathrm{~F}$ & $38,3.6$ & 14 & 14 & 2.8 & $\begin{array}{l}\text { c.2228 A > C,p.Q743P } \\
\text { c.1726 G } \rightarrow \text { A, (p.G576S), heterozy- } \\
\text { gous } \\
\text { c.1935C } \rightarrow \text { A, (pD645E), heterozy- } \\
\text { gous }\end{array}$ \\
\hline 18 & M & $39,3.1$ & 6 & 6 & 2.5 & $\begin{array}{l}\text { c. } 2238 \mathrm{G} \rightarrow \mathrm{C} \text {, (p.W746C), heterozy- } \\
\text { gous } \\
\text { c.1726 G } \rightarrow \text { A, (p.G576S), heterozy- } \\
\text { gous } \\
\text { c.1935C } \rightarrow \text { A, (pD645E), heterozy- } \\
\text { gous }\end{array}$ \\
\hline 19 & M & $38,3.8$ & 7 & 8 & 2 & $\begin{array}{l}\text { c. } 1935 \mathrm{C} \rightarrow \mathrm{A} \text {, (p.D645E), homozy- } \\
\text { gous } \\
\text { c.1726 G } \rightarrow \text { A, (p.G576S), homozy- } \\
\text { gous }\end{array}$ \\
\hline Mean (SD) & & & $10.0(3.42)$ & $11.05(4.31)$ & $5.46(2.33)$ & \\
\hline
\end{tabular}

F, female; M, male; GA, gestational; BBW, birth body weight; and SD: standard deviation

\section{Results \\ Subjects}

Nineteen patients with IOPD were included in the current study. Table 1 summarizes the demographic features of each of the patients. All the patients received their first ERT within $4 \mathrm{~h}$ of admission at a mean age of 11.05 days (range $6-23$ days).

\section{Characteristics of hearing loss}

Table 2 summarizes the auditory test results of the patients. All the patients except one underwent newborn hearing screening at birth; sixteen patients were recorded as having normal values for the hearing screenings, two patients had hearing impairment, and one patient was not screened for hearing. The ages of the patients at their last hearing tests ranged from 2 to 9.5 years old $(5.46 \pm 2.33)$. At the most recent assessment, pure-tone audiometry (PTA) or conditioned behavioral audiometry showed that 1 child had a mild unilateral hearing impairment $(33 \mathrm{~dB})$ and 1 had a moderate mixed-type hearing impairment according to the ASHA hearing classification system. Two patients had conductive hearing loss with an air-bone conduction gap of $15 \mathrm{~dB}$, which was suggestive of chronic middle ear dysfunction. The TABR showed that 2 patients had mild bilateral hearing loss (35$40 \mathrm{~dB} \mathrm{nHL}$ ).

\section{Discussion}

In this study, we reported the hearing test results of the IOPD patients, and we found that the patients in our cohort had early ERT initiation time and a lower hearing impairment rate (with an average ERT initiation time of 11.05 days and $31.6 \%$ hearing impairment in the last evaluation after treatment). To our knowledge, this is the largest cohort of patients to be investigated for the audiological characteristics of IOPD after receiving early ERT.

Hearing loss in IOPD may be sensorineural, conductive, or a mixed type. In the present study, sensorineural hearing loss is the most common type, which is consistent with earlier studies [12, 22]. Martin et al. first recognized both central and peripheral nervous system dysfunctions caused by glycogen storage through anatomopathological study [29]. Kamphoven et al. first reported their inference about inner ear involvement via otoacoustic change in IOPD patients in 2004. They found abnormal glycogen storage in spiral ganglion cells, supporting cells, stria 
Table 2 Summary of audiometric results for the 19 IOPD patients at birth and after enzyme replacement therapy

\begin{tabular}{|c|c|c|c|c|c|c|c|c|}
\hline \multirow[t]{2}{*}{$\begin{array}{l}\text { Patient no. } \\
(n=19)\end{array}$} & \multirow[t]{2}{*}{$\begin{array}{l}\text { Hearing screen } \\
\text { (T-ABR) right/left (dB) }\end{array}$} & \multirow[t]{2}{*}{ OAE } & \multirow[t]{2}{*}{$\begin{array}{l}\text { Age of last hearing } \\
\text { exam (year) }\end{array}$} & \multicolumn{2}{|c|}{$\begin{array}{l}\text { Average hearing } \\
\text { threshold (dB) }(500, \\
1000,2000 \mathrm{~Hz})\end{array}$} & \multicolumn{2}{|c|}{ Tym (right/left) } & \multirow[t]{2}{*}{$\begin{array}{l}\text { Post-ERT hearing loss } \\
\text { type } \mathrm{e}^{\mathrm{a}, \mathrm{b}}\end{array}$} \\
\hline & & & & Right & Left & Right & Left & \\
\hline 1 & Pass & + & 7.5 & 21.7 & 21.7 & $A$ & $A$ & Normal \\
\hline 2 & NA & + & 6.7 & 25.0 & 33.3 & A & A & Single ear SNHL, Mild \\
\hline 3 & Pass & - & 6.8 & 41.7 & 45.0 & C & C & Bil. mixed HL, Moderate \\
\hline 4 & Pass & + & 1.2 & 21.7 & 21.7 & A & A & Normal \\
\hline 5 & Pass & + & 5.5 & 16.7 & 15.0 & A & A & Normal \\
\hline 6 & Pass & + & 5.4 & 16.7 & 15.0 & A & A & Normal \\
\hline 7 & Pass & + & 4.7 & 13.3 & 10.0 & A & A & Normal \\
\hline 8 & Pass & + & 4.8 & 20.0 & 13.3 & $A$ & A & Normal \\
\hline 19 & Pass & + & 4.9 & 25.0 & 23.3 & A & A & Normal \\
\hline 10 & Pass & NA & 4.3 & 26.7 & 28.3 & B & B & Bil. cond. HL, Mild \\
\hline 11 & Pass & NA & 4.7 & 26.7 & 26.7 & A & A & Bil. SNHL, Mild, \\
\hline 12 & Pass & + & 3.1 & 15.0 & 15.0 & A & A & Normal \\
\hline 13 & Pass & + & 2.8 & 20.0 & 20.0 & A & A & Normal \\
\hline 14 & Pass & + & 1.1 & 25.0 & 25.0 & A & A & Normal \\
\hline 15 & Failed & - & 1.1 & 35.0 & 35.0 & A & A & Bil. SNHL, Mild \\
\hline 16 & Pass & + & 1.8 & 20.0 & 20.0 & A & A & Normal \\
\hline 17 & Pass & + & 1.5 & 20.0 & 20.0 & A & A & Normal \\
\hline 18 & Pass & + & 0.8 & 20.0 & 20.0 & A & A & Normal \\
\hline 19 & Failed & + & 0.3 & 40.0 & 40.0 & A & A & Bil. SNHL, Mild \\
\hline
\end{tabular}

T-ABR, threshold auditory brainstem evoked response; OAE, otoacoustic emission; Tym., tympanogram; HL, hearing loss; cond., conductive; SNHL, sensorineural hearing loss; bil., bilateral; ABG, air-bone conduction gap; + , present; -, absent; and NA, not applicable

${ }^{a}$ ASHA definition of the degree of hearing loss (Clark 1981): The hearing loss degree was classified as normal $(<-10 \leqq 15 \mathrm{~dB} \mathrm{HL})$, slight $(>15 \leqq 25 \mathrm{~dB} H \mathrm{~L})$, mild $(>25 \leqq$ $40 \mathrm{~dB} \mathrm{HL})$, moderate $(>40 \leqq 55 \mathrm{~dB} \mathrm{HL})$, moderate severe $(>55 \leqq 70 \mathrm{~dB} \mathrm{HL})$, severe $(>70 \leqq 90 \mathrm{~dB} \mathrm{HL})$, or profound $(>90 \mathrm{~dB} \mathrm{HL})$ hearing loss

${ }^{b}$ Conductive component in case of an air-bone gap of $\geq 15 \mathrm{~dB}$

vascularis, and both the inner and outer hair cells of the cochleas in GAA knockout mice, illustrating the possible mechanism of inner ear involvement [12, 30]. Kishnani et al. also found missing OAE and aberrant wave latencies for the ABR in some patients with Pompe disease [13]. In our cohort, 5 of 6 hearing loss patients had sensorineural hearing loss, two of whom failed the newborn hearing screening after birth. Case 3 did not receive a newborn hearing screening due to a personal reason and had single-ear sensorineural hearing loss upon follow-up. The cases who were congenitally hearing impaired may be related to Pompe disease.

Conductive hearing loss can also be observed in patients with Pompe disease [12, 15, 21, 31]. GAA deficiency causes an abnormal accumulation of lysosomal glycogen in many cell types, most notably in skeletal muscle, leading to cell and tissue dysfunction. Even with ERT, which reverses the myopathy of the respiratory and cardiac muscle tissue, some phenotypes such as ptosis, dysphagia and speech disorders may still occur, probably due to the unresponsiveness of the responsible small muscles [32]. Otitis media with effusion is commonly seen in
IOPD and is the major cause of conductive hearing loss. Van Capelle et al. reported on 11 IOPD patients who received ERT; after 1-6 years of ERT, $90.9 \%$ of them had hearing impairment, and $75 \%$ of all hearing tests showed conductive hearing loss [22]. They inferred that the cause of mixed hearing loss was the accumulation of glycogen in the tensor veli palatini muscle during gestation. Rohrbach et al. reported one IOPD patient who received ERT at the age of 8 weeks and responded as type B to tympanometry when followed up at the age of 8 months, improving in behavioral audiometry after the paracentesis of both ears [21]. Chien et al. reported that $60 \%$ of their IOPD patients who received ERT at an average age of 21.60 days (6-34 days) had hearing impairments, including 4 conductive types and 2 mixed types. In addition, 5 of the 6 children received ventilation tube insertion as a primary treatment $[15,31]$. In our cohort, only $10.5 \%$ ( 2 of 19 cases) of the patients were found to have conductive hearing loss, and none of them received ventilation tubes. The relatively low rate of conductive hearing impairment was probably due to the effect of early 
Table 3 Hearing outcomes among IOPD studies

\begin{tabular}{|c|c|c|c|c|c|c|c|c|c|}
\hline \multirow[t]{2}{*}{ Authors } & \multirow[t]{2}{*}{ Year } & \multirow[t]{2}{*}{ Country } & \multirow{2}{*}{$\begin{array}{l}\text { Patient } \\
\text { no. }\end{array}$} & \multicolumn{2}{|c|}{ Gender } & \multirow{2}{*}{$\begin{array}{l}\text { Age of ERT } \\
\text { (day) }\end{array}$} & \multirow[t]{2}{*}{ Hearing exam tool } & \multirow[t]{2}{*}{ Hearing outcome } & \multirow{2}{*}{$\begin{array}{l}\text { Hearing } \\
\text { impairmen } \\
\text { no. (ratio) }\end{array}$} \\
\hline & & & & Male & $\overline{\text { Female }}$ & & & & \\
\hline Kamphoven [12] & 2004 & Netherlands & 4 & NA & NA & NA & Tym, OAE, ABR, PTA & $\begin{array}{l}4 \text { hearing deficits } \\
(30-70 \mathrm{~dB})\end{array}$ & $4(4 / 4)$ \\
\hline Kishnani [13] & 2006 & USA & 8 & 4 & 4 & 184.13 & $O A E, A B R$ & 5 hearing deficits & $5(5 / 8)$ \\
\hline Rohrbach [21] & 2010 & Switzerland & 1 & 0 & 1 & 56.00 & Tym, OAE, ABR, CPA & Mixed & $1(1 / 1)$ \\
\hline van Capelle [20] & 2010 & Netherlands & 11 & 5 & 6 & 87.55 & Tym, OAE, ABR & $\begin{array}{l}10 \text { hearing deficits } \\
(30-90 \mathrm{~dB})\end{array}$ & $10(10 / 11)$ \\
\hline Ebbink [20] & 2012 & Netherlands & 10 & 5 & 5 & 91.80 & NA & $\begin{array}{l}9 \text { hearing deficits } \\
(30-90 \mathrm{~dB})\end{array}$ & $9(9 / 10)$ \\
\hline Hahn [23] & 2015 & Germany & 23 & 13 & 10 & 103.83 & NA & $\begin{array}{l}43 \% \text { deceased } 3 \text { hear- } \\
\text { ing impairment }\end{array}$ & $3\left(N A^{a}\right)$ \\
\hline Chien15 & 2015 & Taiwan & 10 & NA & NA & 21.60 & NA & 4 conductive, 2 mixed & $6(6 / 10)$ \\
\hline Hsueh & 2021 & Taiwan & 19 & 6 & 13 & 11.05 & $\begin{array}{l}\text { Tym, OAE, ABR, PTA, } \\
\text { CPA }\end{array}$ & $\begin{array}{l}2 \text { conductive, } 1 \text { mixed, } \\
4 \text { sensorineural }\end{array}$ & $6(6 / 19)$ \\
\hline
\end{tabular}

ABR, auditory brainstem evoked response; Tym, tympanogram; OAE, otoacoustic emission; PTA, pure tone audiometry; CPA, conditioned play audiometry; and NA, not applicable

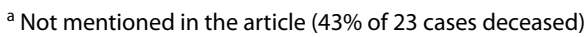

ERT, which prevented or decelerated the dysfunction of the Eustachian tubes or other middle ear muscles.

The natural course of IOPD without ERT would be progressive cardiomyopathy and generalized myopathy or muscular hypotonia [33]. Furthermore, most IOPD patients would suffer from disease progression leading to respiratory failure within the first year of life $[2,16]$. ERT, however, not only enhances overall survival $[4,15$, $20,22]$ but also improves motor and cognitive functions in patients with IOPD [25, 34]. Our previous studies also showed that early ERT can preserve the long-term outcomes of patients with IOPD, including their motor and cognitive functions [25, 35]. While most studies showed dissatisfactory hearing results even after ERT, we reported better hearing performance in our cohort. Previous TVGH data reported by Yang et al. in 2016 showed normal hearing results in 14 patients [25]. By including and following those 14 patients with a thorough hearing test battery and adding 5 additional patients to the current cohort, we found that 2 children developed sensorineural hearing loss, 3 developed conductive hearing loss, and 1 developed mixed hearing loss. The better hearing outcomes reported in our cohort indicate that early ERT could have a positive effect not only on the development of the cochlear and nervous systems but also on the muscular components associated with Eustachian tube or middle ear function.

Although impaired hearing function has been reported in patients with IOPD, many studies mentioned neither the test battery used for the hearing evaluations nor the criteria used to report the degree of hearing loss, thus making it difficult to compare the results among different groups (Table 3). Hahn et al. in 2015 reported 23 cases of IOPD but mentioned only 3 cases with hearing results [23]. Our study is the largest study (19 cases) to reinforce the detailed information on hearing impairment by performing multiple batteries of hearing examinations, including tympanograms, OAE, ABR, PTA and CPA. We also graded the severity of hearing loss according to the ASHA definition of hearing impairment. Through integrations with adequate hearing tools and grading systems, we may obtain more information on the effect of ERT through longitudinal studies.

It is difficult to compare our outcomes with those of other groups due to a lack of detailed hearing data from their studies. Several reasons may underlie the better hearing outcomes obtained in the current study. The racial difference should be considered first. The cohorts of both Chien et al. and our study are from Asian populations [15], and the different genetic background from the subjects of most other studies may contribute to different results. In addition, the large-scale newborn screening program and national insurance coverage of enzyme replacement therapy for Pompe disease in Taiwan may promote earlier initiation of treatment and better hearing outcomes. By combining the 2 cohorts from Taiwan, we propose that starting ERT early after birth can lead to better hearing outcomes than late treatment. Additionally, the lower rate of hearing impairment (31.6\%) in our cohort (ERT starting at 11.05 days after birth) group than in Chien's study [15] (60\%, 20.60 days after birth) further suggests the benefit of early ERT within two weeks for the IOPD patients. And, after 10 years treatment, no IOPD patients in our series needed any kind of hearing aids. Our study may enhance awareness of early intervention before 
hearing-related morbidities can develop in patients with IOPD.

Our study has several limitations. First, since Pompe disease is rare, a small sample size is an inevitable issue. In addition, ERT was first approved for Pompe disease treatment in Taiwan in 2006, and all the followup instances have taken place since then, limiting the length of the follow-up period to date. However, our study is one of the largest cohorts to provide data on both early ERT treatment and hearing examination results. Third, there is a paucity of direct evidence to show whether better hearing results after ERT are due to reduced glycogen accumulation in the auditory system. In fact, the blood-labyrinth barrier, which is similar to the blood-brain barrier, may limit the effects of the recombinant enzymes used for ERT [36-38]. Further pathological or radiological studies may be required to study the mechanism of hearing preservation in the future. Last, control group patients are difficult to include because ERT is covered by the National Health Insurance, and early ERT treatment has been the gold standard in Taiwan.

\section{Conclusions}

Our study is the largest cohort to provide detailed data of hearing outcomes in IOPD patients who received early ERT treatment. Early diagnosis and early initiation of ERT within two weeks after birth appear to contribute to improved hearing outcomes for patients with IOPD. Clinicians should be vigilant for the hearing issues associated with IOPD and intervene early if any hearing impairment occurs in their IOPD patients.

\section{Acknowledgements}

We are grateful for the highly professional work of the staff at the Genetic Counselling Center at Taipei Veterans General Hospital. This study was supported by grants from Taipei Veterans General Hospital (V108C-145, V109C135) and the Ministry of Science and Technology, Taiwan (MOST 108-2321-B075-003 and MOST 109-2321-B-075-001).

\section{Authors' contributions}

CYF conceptualized and designed the study, coordinated and supervised data collection, drafted and wrote the initial manuscript, and revised the manuscript critically for its intellectual content. NDM conceptualized and designed the study, coordinated and supervised data collection, and revised the manuscript critically for its intellectual content. HCY conceptualized and designed the study, drafted and wrote the initial manuscript, collected the data, performed the initial analyses, and revised the manuscript critically for its intellectual content. $\mathrm{HCY}$ coordinated and supervised data collection and revised the manuscript critically for its intellectual content. YCF conceptualized and designed the study and coordinated and supervised data collection. CHL designed the study and coordinated the acquisition and interpretation of the data. CCC drafted the initial manuscript, collected the data, and performed the initial analyses. LWS coordinated data collection and revised the manuscript critically for its intellectual content. WSL performed all the data analyses and data interpretation. All authors read and approved the final manuscript.
Funding

This study was supported by grants from Taipei Veterans General Hospital (V108C-145, V109C-135) and the Ministry of Science and Technology, Taiwan (MOST108-2321-B-075-003 and MOST109-2321-B-075-001).

\section{Availability of data and materials}

Detailed data can be found in the "Methods" section.

\section{Declarations}

\section{Ethics approval and consent to participate}

The Institutional Review Board (IRB) of the Taipei Veterans General Hospital approved this study (IRB No.2020-11-004AC). All procedures performed in studies involving human participants were in accordance with the ethical standards of the institutional and/or national research committee and with the 1964 Helsinki Declaration and its later amendments or comparable ethical standards.

\section{Consent for publication \\ Not applicable.}

\section{Competing interests \\ None.}

\section{Author details}

${ }^{1}$ Department of Otorhinolaryngology-Head and Neck Surgery, Taipei Veterans General Hospital Yuli Branch, Hualien County, Taiwan. ${ }^{2}$ Department of Otolaryngology_-Head and Neck Surgery, Taipei Veterans General Hospital, Taipei, Taiwan. ${ }^{3}$ Faculty of Medicine, National Yang Ming Chiao Tung University, Taipei, Taiwan. ${ }^{4}$ Department of Pediatrics, Taipei Veterans General Hospital, No. 201, Sec. 2, Shipai Rd., Beitou District, Taipei City 11217, Taiwan. ${ }^{5}$ School of Medicine, National Yang Ming Chiao Tung University, Taipei, Taiwan. ${ }^{6}$ Department of Speech Language Pathology and Audiology, National Taipei University of Nursing and Health Sciences, Taipei, Taiwan. ${ }^{7}$ Department of Biomedical Engineering, National Yang Ming Chiao Tung University, Taipei, Taiwan. ${ }^{8}$ Department of Medical Research, Taipei Veterans General Hospital, No. 201, Sec. 2, Shipai Rd., Beitou District, Taipei City 11217, Taiwan. ${ }^{9}$ Institute of Brain Science, National Yang Ming Chiao Tung University, Taipei, Taiwan. ${ }^{10}$ Institute of Clinical Medicine, National Yang Ming Chiao Tung University, Taipei, Taiwan.

Received: 26 December 2020 Accepted: 6 April 2021

Published online: 05 August 2021

\section{References}

1. Hers HG. a-Glucosidase deficiency in generalized glycogen-storage disease (Pompe's disease). Biochem J. 1963;86(1):11-6.

2. Hirschhorn R, Reuser AJJ, et al. Glycogen storage disease type II: acid alpha-glucosidase (acid maltase) deficiency. In: Beaudet A, Scriver C, Sly W, et al., editors. The metabolic and molecular bases of inherited disease. New York: McGraw Hill; 2001. p. 3389-420.

3. Kishnani PS, Howell RR. Pompe disease in infants and children. J Pediatr. 2004;144(5 Suppl):S35-43. https://doi.org/10.1016/j.jpeds.2004.01.053.

4. Chien Y-H, Chiang S-C, Zhang XK, et al. Early detection of Pompe disease by newborn screening is feasible: results from the Taiwan screening program. Pediatrics. 2008;122(1):e39-45. https://doi.org/10.1542/peds. 2007-2222.

5. Lin CY, Hwang B, Hsiao KJ, Jin YR. Pompe's disease in Chinese and prenatal diagnosis by determination of alpha-glucosidase activity. J Inherit Metab Dis. 1987;10(1):11-7. https://doi.org/10.1007/bf01799482.

6. Martiniuk F, Chen A, Mack A, et al. Carrier frequency for glycogen storage disease type II in New York and estimates of affected individuals born with the disease. Am J Med Genet. 1998;79(1):69-72. https://doi.org/10. 1002/(sici)1096-8628(19980827)79:1\%3c69::aid-ajmg16\%3e3.0.co;2-k.

7. Ausems MG, Verbiest J, Hermans MP, et al. Frequency of glycogen storage disease type II in The Netherlands: implications for diagnosis and genetic counselling. Eur J Hum Genet EJHG. 1999;7(6):713-6. https://doi.org/10. 1038/sj.ejhg.5200367. 
8. Poorthuis BJ, Wevers RA, Kleijer WJ, et al. The frequency of lysosomal storage diseases in The Netherlands. Hum Genet. 1999;105(1-2):151-6. https://doi.org/10.1007/s004399900075.

9. Meikle PJ, Hopwood JJ, Clague AE, Carey WF. Prevalence of lysosomal storage disorders. JAMA. 1999;281(3):249-54. https://doi.org/10.1001/ jama.281.3.249.

10. Pinto $R$, Caseiro $C$, Lemos $M$, et al. Prevalence of lysosomal storage diseases in Portugal. Eur J Hum Genet EJHG. 2004;12(2):87-92. https://doi. org/10.1038/sj.ejhg.5201044.

11. van der Beek NAME, Verschuure $H$, Reuser $A J J$, van der Ploeg AT, van Doorn PA, Poublon RML. Hearing in adults with Pompe disease. J Inherit Metab Dis. 2012;35(2):335-41. https://doi.org/10.1007/ s10545-011-9396-3.

12. Kamphoven JHJ, de Ruiter MM, Winkel LPF, et al. Hearing loss in infantile Pompe's disease and determination of underlying pathology in the knockout mouse. Neurobiol Dis. 2004;16(1):14-20. https://doi.org/10. 1016/j.nbd.2003.12.018.

13. Kishnani PS, Hwu W-L, Mandel H, et al. A retrospective, multinational, multicenter study on the natural history of infantile-onset Pompe disease. J Pediatr. 2006;148(5):671-6. https://doi.org/10.1016/j.jpeds.2005.11. 033.

14. Yoshida T, Awaya T, Jonouchi T, et al. A skeletal muscle model of infantile-onset Pompe disease with patient-specific iPS cells. Sci Rep. 2017;7(1):13473. https://doi.org/10.1038/s41598-017-14063-y.

15. Chien $\mathrm{Y}-\mathrm{H}$, Lee $\mathrm{N}-\mathrm{C}$, Chen $\mathrm{C}-\mathrm{A}$, et al. Long-term prognosis of patients with infantile-onset Pompe disease diagnosed by Newborn screening and treated since birth. J Pediatr. 2015;166(4):985-991.e2. https://doi.org/10. 1016/j.jpeds.2014.10.068.

16. van den Hout HMP, Hop W, van Diggelen OP, et al. The natural course of infantile Pompe's disease: 20 original cases compared with 133 cases from the literature. Pediatrics. 2003;112(2):332-40. https://doi.org/10. 1542/peds.112.2.332.

17. Kishnani PS, Corzo D, Nicolino M, et al. Recombinant human acid a-glucosidase: major clinical benefits in infantile-onset Pompe disease. Neurology. 2007;68(2):99-109. https://doi.org/10.1212/01.wnl.00002 51268.41188.04.

18. Slonim AE, Bulone L, Ritz S, Goldberg T, Chen A, Martiniuk F. Identification of two subtypes of infantile acid maltase deficiency. J Pediatr. 2000;137(2):283-5. https://doi.org/10.1067/mpd.2000.107112.

19. ACMG Work Group on Management of Pompe Disease, Kishnani PS, Steiner RD, et al. Pompe disease diagnosis and management guideline. Genet Med Off J Am Coll Med Genet. 2006;8(5):267-288. https://doi.org/10. 1097/01.gim.0000218152.87434.f3

20. Ebbink BJ, Aarsen FK, van Gelder CM. Cognitive outcome of patients with classic infantile Pompe disease receiving enzyme therapy. Published online 2012:7.

21. Rohrbach M, Klein A, Köhli-Wiesner A, et al. CRIM-negative infantile Pompe disease: 42-month treatment outcome. J Inherit Metab Dis. 2010;33(6):751-7. https://doi.org/10.1007/s10545-010-9209-0.

22. van Capelle Cl, Goedegebure A, Homans NC, Hoeve HLJ, Reuser AJ, van der Ploeg AT. Hearing loss in Pompe disease revisited: results from a study of 24 children. J Inherit Metab Dis. 2010;33(5):597-602. https://doi.org/10 1007/s10545-010-9144-0.

23. Hahn A, Praetorius S, Karabul N, et al. Outcome of patients with classical infantile pompe disease receiving enzyme replacement therapy in Germany. JIMD Rep. 2015;20:65-75. https://doi.org/10.1007/8904_2014_392.

24. Yang C-F, Liu H-C, Hsu T-R, et al. A large-scale nationwide newborn screening program for Pompe disease in Taiwan: towards effective diagnosis and treatment. Am J Med Genet A. 2014;164A(1):54-61. https:// doi.org/10.1002/ajmg.a.36197.

25. Yang $C-F$, Yang $C C$, Liao $\mathrm{H}-\mathrm{C}$, et al. Very early treatment for infantile-onset Pompe disease contributes to better outcomes. J Pediatr. 2016;169(174180):e1. https://doi.org/10.1016/j.jpeds.2015.10.078.

26. Clark JG. Uses and abuses of hearing loss classification. ASHA. 1981;23(7):493-500.

27. Viswanathan $N$, Vidler M, Richard B. Hearing thresholds in newborns with a cleft palate assessed by auditory brain stem response. Cleft Palate-Craniofacial J Off Publ Am Cleft Palate Craniofacial Assoc. 2008;45(2):187-92. https://doi.org/10.1597/06-078.1.

28. Jerger J. Clinical experience with impedance audiometry. Arch Otolaryngol Chic III 1960. 1970;92(4):311-24. https://doi.org/10.1001/archotol. 1970.04310040005002.

29. Martin JJ, de Barsy T, van Hoof F, Palladini G. Pompe's disease: an inborn lysosomal disorder with storage of glycogen. A study of brain and striated muscle. Acta Neuropathol (Berl). 1973;23(3):229-44. https://doi.org/ $10.1007 /$ bf00687878

30. Xu X, Negandhi J, Min W, et al. Early enzyme replacement therapy improves hearing and immune defects in adenosine deaminase deficient-mice. Front Immunol. 2019;10:416. https://doi.org/10.3389/ fimmu.2019.00416.

31. Zeng Y-T, Hwu W-L, Torng P-C, et al. Longitudinal follow-up to evaluate speech disorders in early-treated patients with infantile-onset Pompe disease. Eur J Paediatr Neurol. 2017;21(3):485-93. https://doi.org/10.1016/j. ejpn.2016.12.004.

32. van Gelder CM, van Capelle Cl, Ebbink BJ, et al. Facial-muscle weakness, speech disorders and dysphagia are common in patients with classic infantile Pompe disease treated with enzyme therapy. J Inherit Metab Dis. 2012;35(3):505-11. https://doi.org/10.1007/s10545-011-9404-7.

33. Kanters TA, Hagemans MLC, van der Beek NAME, Rutten FFH, van der Ploeg AT, Hakkaart L. Burden of illness of Pompe disease in patients only receiving supportive care. J Inherit Metab Dis. 2011;34(5):1045-52. https://doi.org/10.1007/s10545-011-9320-x.

34. Spiridigliozzi GA, Keeling LA, Stefanescu M, Li C, Austin S, Kishnani PS. Cognitive and academic outcomes in long-term survivors of infantileonset Pompe disease: A longitudinal follow-up. Mol Genet Metab. 2017;121(2):127-37. https://doi.org/10.1016/j.ymgme.2017.04.014.

35. Lai C-J, Hsu T-R, Yang C-F, Chen S-J, Chuang Y-C, Niu D-M. Cognitive development in infantile-onset Pompe disease under very early enzyme replacement therapy. J Child Neurol. 2016;31(14):1617-21. https://doi. org/10.1177/0883073816665549.

36. Juhn SK, Rybak LP, Prado S. Nature of blood-labyrinth barrier in experimental conditions. Ann Otol Rhinol Laryngol. 1981;90(2 Pt 1):135-41. https://doi.org/10.1177/000348948109000208.

37. Juhn SK, Rybak LP, Fowlks WL. Transport characteristics of the bloodperilymph barrier. Am J Otolaryngol. 1982;3(6):392-6. https://doi.org/10. 1016/s0196-0709(82)80016-1.

38. Shi X. Physiopathology of the cochlear microcirculation. Hear Res. 2011;282(1):10-24. https://doi.org/10.1016/j.heares.2011.08.006.

\section{Publisher's Note}

Springer Nature remains neutral with regard to jurisdictional claims in published maps and institutional affiliations. 